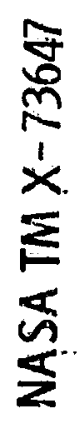

(NASA-TM-X-73647) ATMOSPHERIC EFFECTS ON INLETS FOR SUEERSONIC CRUISE AIRCRAFT (NASA) $14 \mathrm{P}$ HC AO2/MF $\mathrm{BO}$. CSCL ?1A

N 78- 10026

Uniclas --

\title{
ATMOSPHERIC EFFECTS ON INLETS FOR SUPERSONIC CRUISE AIRCRAFT
}

by Gary L. Cole

Lewis Research Center

Cleveland, Ohio 44135

TECHNICAL PAPER to be presented at the - Thireenth Propulsion Conference.. cusponsored by the American Institute of Aeronautics and Astronautics and the Society of Automotive Engineer's Orlando, Florida, Tuly 11-13, 1977

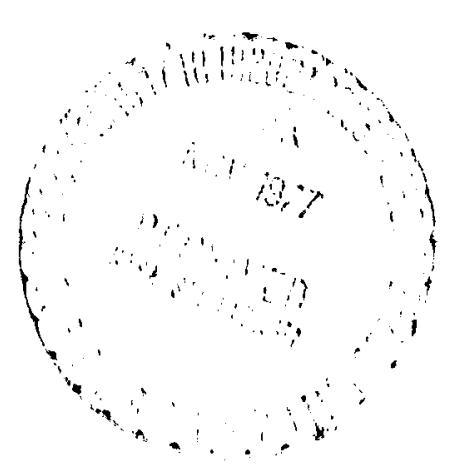




\section{Abstract.....}

An analysis, that reallsticaliy simulates mixed-compression 1nlet dynamic behavior in the vicinity of unstart, was used to Investigate time response of an inlet's normal shock to 1ndependent disturbances tn ambient temperature and pressure and relative velocity (longltudinal gust), with and without inlet controls active. The results indlcate that atmospheric disturbances may be more important than internal disturbances in setting inlet controls requirements. This is because they are usually not anticipated.. and because normal shock response to rapld atmospheric disturbances is not attenuated by tie inlet, as it is for engine induced disturbances. However, before tinlet control requirements can be fully assessed, more statistics on extreme atmospheric disturbances are needed.

\section{Introduction.}

An efficient propulsion system will be a key factor in the development of an economically viable supersonic cruise aircraft. New engine concepts known as vartable cycle engines are being defined by studies under contract to NASA. 1 a balanced program requires attention to the problems of inlets, especially since they are quite-important for cruise Mach numbers in the range of 2.2 to 2.7 . To minimize cowl drag and provide efficient propulston system. performance at those Mach numbers requires the use of a mixed-compression inlet (1.e., an inlet with internal supersonic area contraction). Unfortunately, when such an inlet operates at its peak performance it is also on the verge of an instability termed unstart. The unstart transient can be accompanfed by many adverse effects on the inlet and engine, which can also serfously affect aircraft stability. Such an event would be unacceptable on a commercial transport. Therefore, the problem of maximizing inlet performance while minimizing or elfminating the unstart problem is of concern.

An 1nlet can encounter both Internal (e.g., engine induced) or external (e.g., atmosphèric induced) disturbances that can cause unstart. Engine transients, such as a throttle change or afterburner 11ght are usually antlcipated, and appropriate control action can be inftiated to prevent a potentfal unstart. Also, such transients can be investigated in wind tunnel tests.. Numerous experImental programs have been conducted at Lewis Research Center and elsewhere to Invest1gate inlèt response to Internal disturbances and approprlate control actions. A recent wind.tunnel program at Lewis was conducted to investigate a mixedcompression 1nlet/turbofan englne combination. ${ }^{2}$

Atmospheric type disturbances are of greater concern because they are generally unexpected, giving less time for controls to respond. Very little
Information relating to atmospheric effects on mixed-compresston inlets in filght has been acquitred. And furthertore, simulation of atmospheric disturbances -in.a wind tunnel is difficult. One recent paper does cile flight experience of supersonic crulse aircraft indicating that severe atmospheric transients can have serfous effects on the flight path and propulsion system. ? Some inlet normalshock responses to simulated gusts have been obtalned in wind tunnels by oscillating wedges and flat plates upstream of the inlet. 4,5 An analytical procedure for predicting frequency of unstarts using a linear inlet nodel and a power spectral density representation of atmospheric perturbations is given by Barry. 6

This paper is aimed at directing attention to time response effects of atmospheric-type disturbances on inlets and some implications regarding inlet controls. Results are presented from a study that used a inear dynamic analysis 7,8 modified for a significant nonlinearity to simulate a mixedcompression inlet. Transient disturbances in ambi- ent temperature and pressure and wind gusts are considered independently at the inlet cruise Mach number of 2.5 .

A brief description of the inlet simulation and a discussion of modifications and limitations for this study are followed by a description of che assumed inlet characteristics and operating conditions. Results are presented showing the maximum amplitude of a triangular-wave disturbance, that does not cause inlet unstart, as a function of disturbance pulse width. Unstarts initiated by normal shock excursions upstream of the inlet throat and by throat choking (reduction in throas Mach number) with and without inlet control, were investigated.

\section{Inlet Analysis}

Only a brief description of the analysis, selected for simulating the mixed-compression inlet, w1ll be given becalise. It is described in.detail elsewhe re. 7,8 Instead, the validity of the simulation and 1 ts 1 inftations will be given greater attention.

The simulation is based on a linear (small perturbation) one-dimensional mathematical analysis. The analysis was inftially derived for application to 1nternal alrflow perturbations 7 and later modified for application to flow-fleld perturbations upstream of the normal shock. ${ }^{8}$ The analysis time dependent vartables are total pressure, mass-flow rate, entropy and a moving normal shock that srparates the supersonic and subsonic flow regions. The inlet geometric-flow-area variation is approximated by constant-area cylindrical sections which result in one-dimenstonal wave equations. Wave equations are used to represent both. the subsonic and supersonic flow regions. Hence, discontinuitles and losses in total pressure due to oblique shock waves in the supersonic portionareneglecter.

*Aerospace Engineer, find Tunnel and Flight-DLviston. Member AIAA.

STAR category 07 


\section{ORIGINAL PAGE IS}

\section{OF POOR QUAIITY}

The analysts was previounly vertfied for smali perturbation results with the normal shock operatIng polat at a supercritical position (away from unstart). where shock posttion t.s reasonably linear with perturbation amplitude. Frequency responses of the inlet normal sliock and subsonlc duct static pressures to Internal airflow variations calculated with the arialysis 7 have been shown to give good agreement with published 5 and unpublished experimental results. Good agroèmẽnt wảs also demonstrated with a limited amount of expecimental data for exterrial alrflow perturbations.8 For frequency response data 1t was generally found that phase angle agreement was better ttian, that for amplitude. Amp11tude agreement was 1mproved by factoring steady-state experfmental dala 1nto the allalysis. 7,8 This provides a méans of compensating for boundarylayer effects not accounted for when the duct geometrlć-flow-area variation is used.

To further evaluate the merlt of the linear analysts for external perturbations, it was compared ${ }^{8}$ to frequency response results obtained from a one-dimensional method-of-characterdstics solu“ t1on. 6 Pháse angle ànd amplitude agreement-was perfect over.the frequency range of 5 to $40 \mathrm{~Hz}$ for which method-of-characteristic data were calculated. of course neither analysis includes viscous effects. and the problem is not stmply one-dimensional.

In order to provide a more realistic simulan tion of inlet operation in the vicinity of unstart. the basic analysis 7,8 was modified by adding a nonlinearity that is associated with the rate-ofchange of duct flow area $(\Delta A / \Delta x)$. This can be explained with the ald of Fig. 1. The linear analysis assumes that the normalized rate-of-change of duct flow area $-(\Delta A / A) /\left(\Delta x / R_{C}\right)$ is constant and equal to the value at the shock operating point. Actually, the value of that parameter changes with shock pesition, primarily because of the change in $\Delta A / \Delta x$. As the shock moves forward $\Delta A / \Delta x$ varles from a positive value at . the shock operating point to zero at the throat and then negative upstream of the. throat. where the shock. is unstable, resulting in unstart. The variation. of $(\triangle \mathrm{A} / \mathrm{A}) /\left(\Delta \mathrm{x} / \mathrm{R}_{\mathrm{c}}\right)$. 1s $\mathrm{s} 1 \mathrm{~g}-$ nificant because the shock position galn to any perturbation is inversely proportional to $(\Delta A / A) /\left(\Delta x / R_{C}\right)$. This nonlinear. effect is included in the analysis for this study by making $(\Delta A / A) /\left(\Delta x / R_{c}\right)$ a continuous -function of shock position measured from the throat station. Th1s.was easler to 1mplement in the analysis and more accurate than using several $(\Delta A / A) /\left(\Delta x / R_{c}\right)$ segments each-having a diffeerent but constant valué..

The nonlinear verston of the analysis - is coinpared in Fig. 2 with data obtained during a wind tunnel program that used an inlet from. $\mathrm{v}_{\mathrm{F}-12}$ atrcraft. The disturbance, composed of a single triangular wave pulse, caused a dècrénse In diffuser exit corrected alrflow, slmulating an engineInducéd disturbance. The-pulse amplitude was ina creased until the maximum value the finlet could tolerate without unstart was found. Analysis rêsults we re obtained from an analog computer version of the linlet simulation. The nonlinéar analysis results wer re obtained in the same manner as the experimental results, whêre the sf ulated inlet steady-statè corrected-airfilow-m -gin from unstair was the same as for the experimented inlet.- The nonlinear analysis predicts unstart by the onset of a rapld upstream excursion of the normal shock, sending the simulation into saturation. The linear

analysis results are bascd on the assumption that the Inlet unstarts when the normal. shock reaches the throat. The maximum disturbance amplitude whtilout unstart is plotied as a function of pulse zeroto-peak time in F1g. 2. As pulse width decreases, the noñlineat analysis, which sliows better agree- ment with the data, predicts that the amplitude required to unstatt the fnlet is greater than for the linear analysis. One reason why the nonl tnear analysis agrees better is because it predicts that the ncrmal shock car move further upstreami. Without unstart as pulse duration decreases. This phenomenon 1s.exhiblted in Fig. 3, which shows time histories of the disturbance and normal slock postition for two pulse widths; the maximum amplitude case is shown for both transients.. Note that for the longer duration ptise, the shock only reaches the throat, whereas for the shorter, pulse it actually travels upstreati of the throat... The conclusion that an inlet will. unstart when the normal shock moves upstream of the throat is drawn from steadystate ae rodynamics. The analysis shows that, under transient conditions, the shock can thake a momentary excursion upstream of the throat withour unstart. The-occurrence of this phenomenon was observed from translent static-prëssure measurements that were obtained during the wind tunnel prograth of $\operatorname{Ref} .9$.

Before 1nvestigating extemal disturbances, additional modifications were made to the analysis reported in Ref.. 8. The modifications include terms to account for changes in supersonic spillage due to changes in. free-stream Mach number and in centerbody position, as well as an effect of centerbody position on normal shock position.

There were no experimental data, comparable to those for-1nternal disturbances, to vertfy the external analysis results. One source of error in the analysis is that interaction of the normal shock with the boundary. layer is not modeled. Shock/ boundary-layer interaction is Important because it can affect conditions upstream of the shock. The interaction could 1nduce unstart due to local choking upstream of. the shock or by. shifting the location of the aerodynamlc throat, which is assumed fixed in the analysis. Another source of analysis error is a set of constant coefficients that affect the gain of normal shock position to a disturbance. The coefficients are functions of Mach number just upstream of the shock, and are based on the value at the shock operating point. However, the Mach number cán change slgnificantly due to ambtent temperature and gust disturbances. Although absolute levels predicted by the analysis may not be exact, the transient-response trends are belleved to be realistic.

The fact that the analysis is one-dimensional 1imfts it to the investigation of longitudinal disturbances. Therefore, consideration of other effects which might contribute to unstart is elfmtnated, including (1) angle of attack changes due to gusts, (2) anglè of attack changés and throat chokIng due to atmospheric 1nduced fllght path changes and structural motion of $\ldots$ the centerbody relative to
the cowi. -

\section{Inlet Characteristics and Operating Poine Conditione}

Supersonic cruise alrcraft studtes for NASA Indicate a crulse Mach number In-the-range of 2.2 
to 2.7. The litlet selected fur this study was a to 2.7. Ted-compresston-type with a destgn Mach number of 2.5. Aetodynamte and geometric charactertstics of 2.5. The lnlet is baged the inlet are shown 10 but with a slightly ghorter subsonic diffuser. Also, for this analysis, it was guctor of about 3.3 to make it comtolets belng slaed for current varlable parable to inlets betho Ihis resulted. In a capturc cycle-cngine designs. Thls resulted ln a captur radius of 79 cm. centerbody to accons system near the diffuser exit an overboard bypass system near the diffuser exit to allow matching of inlet afrflow to engine alrflow demand.

The inlet was assumed to have the following operating point conditions with the centerbody at operating polnt and the overboard bypass closed the cruise position and the cow $1-11 \mathrm{p}, 0$; throat boundary-layer Splliage at- the cow $1-11$, 06 ; compressor-face totalbleed mass-flow ratio 92 ; engine corrected airflow. $194.4 \mathrm{~kg} / \mathrm{sec}$; and.engine corrected airflow margin from unstart, 3.5 percent....

In all cases the simulated inlet.was disturbed ith which were durations at inlet. crudse of 16,764 meters. The corMách 2.5 at an altitude of 16,764 meters. $1 / \mathrm{cm}^{2}$ and respond1

\section{Model of Inlet and Control System}

The inlet. model was based on the ldealized athe 5 . The disturbance was inlet schematic of centerbody tip. conditions but assumed to occur at centerbody tip conterbody and cow 1 ip delay times between the centerbodlage at the cow 1 were neglected. Supersonic spillage at the cow Iip varies with the. corresponding change in Mach number at the centerbody tip. The inlet duct was modeled by one supersonic and two subsonic sections. Transport delay times, used in. the wave equations that govern those sections, were calculated by usling the average Mach number in each section. Average Mach numbers. were found $\mathrm{from} \mathrm{Fig}$. 4. A choked boundary-layer bleed reglon was assumed to choked boundary-layer bleed reglon was of the normal occur across. zero length upstream. of the north changes shock. The amount of bleed could vary with changes in upstrean conditions. A term is Included lithe. analys $1 \mathrm{~s}^{8}$ that allows bleed airflow to vary

$$
\left(\frac{\Delta W_{b 1}}{W_{c}}\right) /\left(\frac{\Delta x_{B}}{R_{c}}\right)=-0.108 \cdots \cdots
$$

where a positive shock displacement occurs in the downstrean direction. The value. is based on experinental data. 10

Using the diffuser area variation curve of Fi. 4, was found that the nomalized rate-ofFig. 4, 1t was flow-area $(\Delta A / A) /\left(\Delta x / R_{c}\right)$ in the change of duct flow-area ( $A / A) /\left(\Delta x / k_{C}\right.$ ) ln the vicinity of the throat varies linearly with distance.. Therrefore the analysis was modifled to make $(\Delta \mathrm{A} / \mathrm{A}) /\left(\Delta \mathrm{x} / \hat{R}_{\mathrm{c}}\right)$ vary directly with shock position measured from the throat, making the analysis nonlinear, rather.than being constant as in the analysis.. Finally, the overboard bypass was as unied to occur across zero lenst exit..

A schematic of the inlet control system is given in Fig. 6. The system, which manipulates the verboard bypass and the centerbody, Is representaof a control for mixed-compresston type inlets.

The oyerboard bypass control is a-closed-1oop stem, the purpose of which is to malutin the post ton of the normal shock at h performance conion of the normal. shock at a hlgh performance conses dition without allowing unstart of the duct pressure ratio the rat of an internal duct staticm $P R$, which is the ratio of an lnternat pressure $P_{t}$. pressure $\mathrm{P}_{d}$ to an. external value $P R_{c o m}$ is scheduled The desired or conmanded value. Mach nuriber is calcuas a function of Mach tumber.... Mach number. lated from Pitot-static probe measurements noves, it causes an error cowl 11p. When the shock moves, the controller. $\left(P R_{\text {com }}-P R\right)$, which is sensed by the controller. The resulting control..action is an increase or decrease in bypass flow unt1l the error is driven to zero. An upstream movement of the normal

The centerbody position control is an open-loop or scheduled systeti. It merely positions the-centeror schedula number. The centerbody body as a function or Much number approxiis moved to keep the throat Mach. number approxtmately constant by varying throat area and super sonic spillage. Throat area and supersonic to a decrease increase when the spike extends, due to

The response of sensors nnd actuators selected for the control system was based on the assumption or the future, actuation hardware will 11mit that, in the future, actuation haxdware with than the control response to a much greater exaus of the sensors. This is basically true Decause of the the .... massive hardware that must be moved. Thexefoce, responses of the Mach and duct. pressure ratio sensors were assumed to be instantaneous relative to the actuators, which would be true of close between transducers. Obviously, long line lengths betwee sensing ports and the transducers would introduce pneumatic lags. In addition, a mismatch of lag tin could cause problems. For. example, an erroneous indication of Mach number would result in a wrong reaction of the control system.

The Erequency dependent portion of the transfer functions governing the response of the bypass and fo position commands, as well centerbody posits controller, are given in $\mathrm{Fig} .6$. as. for the bypass controller, are given in The centerbody is characterized by a second order $\mathrm{lag}$, and the bypass by a first order. 1ag. Bypasses with two different corner frequencles wbp were vestigated. A proportional-plus-integral type

The fonctions by the in The functions enclosed by the dashed 11 computer. in a the schenat1c. would be performed by a they were proflight-application. For this study, they were programmed on the analog computer along with the inlet analysts.

\section{Results and Discussion}

Unstarts initiated by excursions of the normal shock upstream of the throat and by throat choking were investigated analytically with and. whout inlete normal-shock type unstarts wi11 be discussed first.

Normal Shuck Unstarts

With inlet controls inactlve. A comparison of linear and nonlinear analysis results is shown in ORIGINAT PAGE LS. OF POOR QUATITY 
Fig. 7 for Independent disturbanees in amblent temperature, relattve voloctty (longttudinal gust). amblent pressure, and engine corrected atrflow. The disturbance pulses are also 111ustiated. Plus and minus stgns on the ordinate indicate whether the disturbance vartable increased or decreased from its operating polnt value. Tho cholce of aigh was dictated by the requirement for the normal. shock to move upstream toward unstart. The inlet was. assumed to be connected to an engine whose corrected atrflow changes due to changes in air total temperature. The results show that in all. cases the nonlinear analysis predicts greater tolerance to unstart than does the 1 inear analysis as pulsc duration decreases. Hence, a linear analysis would predict a greater frequency of inlet unstarts for a given atmospheric model, indicating a posstble need to operate the inlet nore supercritically (less. efficiently) than necessary. Figure 7 also shows that inlet tolerance to unstart remalns about the same or.decreases with decreasing pulse duration for the external discurbances, whereas it. Increases for the engine disturbance. Thus, bestdes being unexpected, the extetnal disturbances represent a potentially greater control problem because the inlet has less natural immunity to fast disturbances, which. conventional controls are less apt. to respond to. The ambient pressure disturbance resuits are interesting because it does not affect flight Mach. number and has 11ttle or no effect on steady-state shock position. However, a rapid change In ambient pressure, that could be caused by a pasing aircraft for example, does result in significant normal shock displacements (Fig. $7(\mathrm{c})$ ). Of. course, combinations of the external disturbances are likely to occur, which could act to reinforce or cancel each other. Finally, it was found that inlet tolerance to unstart was essentially proportional to engine corrected airflow margin from unstart for ail pulse widths, although it is not shown in Fis. 7 .

Study results were found to be signlficantly effected by engine corrected alrflow sensitivity to total temperature. The inlet is most sensitive to changes in ambient temperature and. gusts berause they cause the greatest changes in total temperature. Therefore, results will be shown only for those two diaturbances. However, all disturbances that induce a normal shock excursion cause. some change in total temperature that 1s-proportional. to the change in shock velocity but this 18 generally less significant. Figure 8 shows a comparison of results obtalned 1gnoring the change in engine corrected airflow with. temperature $\left(K_{\mathrm{T}}=0\right)$ to the results of Flg. 7 for whlch a reprèsentative value of $K_{T}=-1$ was used. When ambient temperature is the disturbance $\left(\mathrm{FI}_{\mathrm{g}} .8(\mathrm{a})\right)$, the results are about the same for short duration pulses, but as pulse duration increases inlet tolerance is greater with the constant corrected al rflow engine $\left(K_{T}=0\right)$. Results for the gust disturbance are shown in F18. $8(b)$ and are about the same for the short duration pulses, as in the ambient temperature case. However, as pulse duration increases, the 1nlet with. the constant corrected alrflow engine becomes less tolerant-to the disturbance, just the opposite of the temperature case. Obviously, the cholce of $\mathrm{K}_{\mathrm{T}}$ greatly affects the results and the relative 1mportance of gust and amblent temperature disturbances. The steady-state value of $K_{T}$ can range in value from -0.2 to -5.0 depending on the englne and its control and operating condition and it can also be a-funetion of frequency. 6 The value of $\mathrm{K}_{\mathrm{T}}=-1$ was selected as a representiltive value and was made Independent of frequency because no apectste engl ne was selected for thiss study. Corficted afrflow changes csuld also result from el igos in lulet total pressure. However, it ls elt that the temperature effect is more important and was therefore selected for lllustration here, It lis apparent that, given a specific engine, a correct representation of its alrflow characteristica is important, espectally for gust and ambient temperature disturbances.

Traces showing the transtent response of normal shock position to triangular wave pulses in ambient - temperature, relative velocity, and ambient pressure are shown in F1g. 9. The transtents were obtained with the same ronlinear analysis as for the results of Fig. 7. The results show that the normal shock vill initially travel upstream when ambient temperature increases and relative: velocity and amblent pressure decrease. This was found to be generally true over. the range of pulse widths tested. The shock is displaced upstream.of the throat without unstart for rapld disturbances like these, as in the case of rapid engine disturbances. Note that the normal shock has a substantial overshoot in the downstream direction for both the relative velocity and ambient pressure disturbances. This was generally observed for pulse zero-to-peak times of 0.1 second or less and indicates that a disturbance of this wave shape but of the opposite sign could unstart the inlet, even though the shock would go downstream intially. The reason for, the overshoot is that the gain of shock position to either the relative velocity disturbance for $\mathrm{K}_{\mathrm{T}}=-1$ (or the ambient pressure disturbance for any $K_{T}$ ), is nearly zero; therefore, after the disturbance stops decreasing, the shock tends to return rapidly to the operating point. The reversal of the disturbances causes shock position to overshoot in the opposite direction. The conclusion is that the disturbances that tend to cause unstart are increases in amblent temperature and decreases in relative velocity and amblent pressure. Figure 7 indicates that the rate of change of ambient pressure and relative velocity must be vexy rapid, aj.though the relative velocity result depends on engine corrected alrflow sensitivity to changes in air total teinperature.

W1th inlet controls active. Results from the nonlinear analysis obtained with both the overboard bypass and centerbody control systems active, are presented in $\mathrm{FIg} .10$, along ifth the results without control from $\mathrm{Flg}$. 7. Results were obtalned for two different bypass corner frequencies $\omega_{b p}$. Also shown are lines indicating the level of disturbance amplitudes that might be expected. In the temperature case (FIg. 10(a)) the expected disturbance level is based on flight data. 6 It represents the worst-case data and was extrapolated for zero-topeak times less than 0.1 second. No probability of occurrence was assoclated with the data. Tho points based on Concorde flight experience ${ }^{3}$ are plotted as the solid symbols along with the calculated time between encounters. The data shows that with thecontrols active, the Inlet should not unstart. However, the inlet does come close to uistart with the slow bypass control in the vicinity of $\Delta T=0.1$ second. Unstarts would occur only when the inlet control ls inactive for disturbance zero-to-peak times greater than 0.1 second.

Regults for the longltudinal gust case are shown 
In Fig. 10(b). The disturbance amplitudes that might be expected are based-on gust criterla used for the cancelled Amertcan SST, and were extrapolated for: $\Delta T^{\prime}$ 's below 0.03 second. A point based. on unpublishĕd YF-12 alicraft flight expertence, obtained during the NASA filight research program, 1is plotted as the solid symbol. No probability of occurrence was assoctated with these data. The data show that no unstart is predicted to occur due to a gust. The faster bypass provides somewhat mora tulerance than does the slow bypass or inlet without control. The latter two curves colncide.-

Resul:s for the amblent pressure case with inlet control using either bypass are not shown because-they were the såme as for the Inlet without control (Fig. 7 (c)). The disturbance criterla for the SST was for passing al rcraft separated by 500 feet. The calculated maximum decrease in pres-sure that occurs is 14 percent in 0.013 sécond.The analysis predicts that such a disturbance would unstart the inlet.

It. should be reall: that the absolute levels predicted by the analysis have. not been verified by experiment. - Data taken during the wind. tunnel program of Ref. 9 Indicated that the actual change in steady-state Mach nutuber (that changed mass-flow. rate but. not..total temperature and pressure) required to unstart that inlet was less than the value predicted by the analysis. One possible explanation is that the shock boundary-layer Interaction caused the inlet to unstart earlier than the analysis predicts. The analysis was found to give much better agreement if constant coefficients, depending on the Mach number just upstream of the normal shock, were based on the average value rather than the inftial value. When that technique was applied to the temperature case (Fig. 10(a)), no significant difference in the analysis steadystate value was found, indicating that the value shown should be nearly correct. However, there were no experimental steady-state data for unstarts due to temperature avallable to verify the analysis. The inlet with the-slow bypass provides only marginal tolerance to unstart due to temperature in the vicinity of $\Delta T=0.1$. The faster bypass system would appear to be adequate even if predicted analysis levels had to be shifted down by 10 to. 20 percent, keeping in mind that the control system sensors were assumed to respond instantaneously. Amblent temperature disturbances appear to be more significant than longltudinal gusts; al though that concluston depends on engine alrflow characteristics (e.g.; thé vălue of $\mathrm{K}_{\mathrm{T}}$ ).. More data are needèd to verify the levels predicted by the analysis and to increase knowledge of expected disturbance levels beffore the bypass requirements can be fully assessed. A gust probe has beèn linstalled on-a NASA YF-12 aircraft in the hope of providing addi-. tional information in this area. 11 One inlet on the al rcraft. is highly instrumented so that inlet response can also be measured.

Therè are several alternatives to consider with respect to bypass requirements. It appears that bypass doors whth a corner frequency on the order of $50 \mathrm{rad} / \mathrm{sec}$ would be required to provide high inlet performance.. This could probably be achleved only by using several individual-bypass valves with their own actuators, hydraulic lines, etc. Such a system would be neceasarily complex, posstbly with low rellabiltty.
An alternate systom that could-provide the same Inlet performaice would be to augment a slow overboard bypass system with a throat-bypass stability system. A throat-bypass system could use tellef-type mechanlcal valves or vortex values to bleed alrflow in the throat regton when thr normal shock-moves upstream toward unstart. Such a system using mechanical valves was tested in a flight hardw ware inlet 9 and found to work very well for both internal. and external disturbances. The valves are self =acting, which elininates sensor lags, and arc fast responding because they are smal1. - The system bleeds little or no alrflow when the shock is at the desired position and could be incorporated as part of the boundary-layer bleed system. Sertous consideration should be given to incorporating a throat-bypass system during the 1nitial design stages of an inlet... -

Maximization of -inlet performance accomplishedby using spectal hardware máy. not be the best overall answer. . Inlet tolerance to unstart can be increased by simply operating it more supercritically with corresponding lower-performance. The alternat1ves must be examined by conducting mission, $\cos t$ and reliability studies before the final choice can be. made.

\section{Throat Chokfing Unstarts}

Unstarts inftlated by throat choking were investigated by means of the 11near analysis. The assumption was that unstart occurred when the throat Mach number decreased from the operating value of 1.24 to 1.0. Since normal-shock/boundary-layer Interaction is not modeled, the shock was assumied to be too far supercritfcal to affect the results. Thus, only centerbody position, which affects throat Mach number, and its control are important. The results are shown. In Fig. 11 with inlet controls active and Inactive. Amblent temperature increases required to unstart the inlet, with or without con. trol, are well above the expected disturbance levels that were shown in Fig. 10(a) and are more than twice the level predicted to initiate unstart due to a normal shock excursion. The same is true for the gust case (Fig. 11(b)) except for the uncon-. trolled inlet at $\Delta T^{\prime} s$ greater than 0.5 second.. Results for ambient pressure disturbances are not shown because they do not affect-throat Mach number significantly.. A throat-bypass stability systern can provide additional protéction against external. disturbances by relleving pressure rises in the throat region and giving the slower acting convent1onal control more time to respond. 9 . In this application it also has the advantage that the stabillty system 1tself does not drive the normal shock upstream toward unstart, which can occur when the centerbody is extended.

The absolute levels predicted by the analysis are agaln in question. Some data were ot talned for the experimental inlet ${ }^{12}$ upon which the study inlet 1s based. Those data Indicate that the $\ln 1 \mathrm{et}$ w111 actually unstart due to a 3.5 percent decrease in Mach number rather than the predicted decrease in veloct ty of 4.7 or increase in temperature of 9.1 percent. A possible reason for the differetice is that boundary-layer scparation occurs inltating unstart before the throat Mach number can decrease continuously to one. Even though the actual value causing unstart 19.1es3 than that predlcted, the throat-choking type unstart appears to be a less serlous problem than that due to a normal simock 
excurston. This conclusion might not be the same If the shock operating point was more supercrittcal.. N.so, angle of attack effects and motions of the centerthody relative to the cowl. finduced by atmozpherte disturbances may compound the throat chokins: problem. In actuality, the two types of unstart may be inseparable because. of shock boundary layer Interaction effects.

\section{Conclusions}

A primarily linear analysis was modffted for a significant geometric nonlinearity to realistically staulate mixed-compression inlet dynamic behavior. in the vicintey of unstart. The allalysis was used to investigate inlet response to independent disturbances in amblent temperature and pressure and relative velocity (longltudinal gust), with and without inlet controis active.

The nonlinear analysis predicts greater inlet tolerance to fast pulse-type disturbances than does the linear-analysis. The main reason is that the nonlinear analysis correctly allows the normal shock. to make mumentary excursions upstream of the throat in response to rapid-disturbances; whereas the. Iinear analysis results are based on. the assumption that the inlet unstarts when the shock reaches the throat. Therefore the linear analysis would predict a greater frequency of unstart for a given atmospheric model, Indicating a possible need to operate the in].et less efficientiy than necessary.

Atmospheric-type disturbances represent a potentially greater inlet control problem than. do engine disturbances. This is because they are usually not anticipated and because rapid disturbances are not attenuated in the inlet like engine disturbances. Ambient temperature disturbani-s were found to be potentially more hazardous than longltudinal gusts. .. However, inlet response to those disturbances is significantly. affected by engine corrected alrflow sensitivity to alr total temperature, indicating that airflow characteris=tics for a specific englne should be properly accounted for. As engine alrflow sensitivity to temperature increases, ambient temperature disturbances become more important relative to gusts. Amblent pressure disturbances are the least significant; although, a large rapid decrease could uncombinations of disturbances are likely to occur., that could act to relnforce or cancell each other.

Longitudinal gusts are more 11kely-to initiate unstart by throat choking... However, disturbance amplitudes required to cause throat choking were found to be greater than those required to initiate unstart by a normal shock excursion, indicating that the latter type unstarts are a more serlous problem. Th1s conclusion could change if shock/ boundary-layer Interaction effects were included in the analysis or if the normal shock operating point had been more supercritical.

It appears that an overboard bypass system w th a corner frequency on the order of $50 \mathrm{rad} / \mathrm{sec}$ or 3 slow bypass system ( $12 \mathrm{rad} / \mathrm{s} ? \mathrm{c}$ ) sugmentéd by a throat-bypasa stability systen $w 111$ be required to provide high inlet performance with low unstart probability. Before inlet controls requirements probabllity. Before lniet controls asesed, more statistics on extreive atmospherlc. disturbances are needed, as well as some vertftcation of absolute levels predicted by the analysis.

$$
\begin{aligned}
& \text { Symbol L1st - } \\
& \text { A } \\
& \text { Lnlet duct flow aren, } \mathrm{cm}^{2} \\
& \mathrm{~A}_{c} \text { Inlet capture area, } \mathrm{cm}^{2}
\end{aligned}
$$

M Mach number.

p total pressure, $N / \mathrm{cm}^{2}$

$P_{R}$ control pressure ratio (F1g. 6)

p static pressure, $\mathrm{N} / \mathrm{cm}^{2}$

$R_{c}$ radius of inlet capture area, $79.2 \mathrm{~cm}$

r. local centerbody or cow1 radius, $\mathrm{cm}$

$s$ - Laplacé varlable, $\sec ^{-1}$.

$\Delta \mathrm{T}$ zero-to-peak time of triàngular wave pulse, sec $T_{a}$

$T_{t}$ air total. temperature, $\mathrm{K}$

u longitudinal velocity of inlet relative to air at centerbody tip, $\mathrm{m} / \mathrm{sec}$ actual alrflow, $\mathrm{kg} / \mathrm{sec}$

$W_{b 1}$ boundary-layer bleed airflow, $\mathrm{kg} / \mathrm{sec}$

$W_{c}$ inlet capture al.rflow, $\mathrm{kg} / \mathrm{sec}$

$W_{\text {ec }}$ engine corrected afrflow, $(W \sqrt{\theta} / \delta)_{\mathrm{eng}}, \mathrm{kg} / \mathrm{sec}$

normal shock displacement from throat. (posttive in cownstream direction), cm

inlet longitudiral coordinate, cm

perturbation quantity

ratio of local total pressurr. to standard sea level pressure

$\theta$

ratio of local total temperature to standard sea lével tẻmperature

$\omega_{\mathrm{bp}}$ overboarci bypass corner frequency, rad/sec

Subscrlpts :

a

av

com

ambient

average

command value

d. In] at duct static

eng englne

s Pitot-static probe static

t P1tot-static probe total 
() Indlcates operating point value of ()

\section{References}

1. Whils,. E., "Varlable-Cycle EngInes for Supersonic Cruise Aircraft," AIAA Paper 76-759, Palo Alto, Calıf́....July 1976.

2. Batterton, P. G., Arpasi, D. J., and Baumbick, R. J., "Digital. Integrated Control. of a Mach 2.5 Mixed-Compression Inlet and ar. Augmented Mixed-Flow Turbofan Engine," NASA TM X-3075, 1974.

3. Schweikhard, W. G., et ai.., "Effects of Atmospheric Conditions on. the Onerating Characteristics of Supersonic Cruise Alrcraft," International Astronautica? Federation, $27 \mathrm{th} \mathrm{Con}^{-}$ gress, Anaheim, Caltf., Paper 76-112, Oct. 1976.

4. "Investigation of Supersonic Transport Engine Inlet Configurations," Loc:heed Alrcraft Corporation, Burbank, Cal1f., LAC-603220, Sept. 1965; also NASA CR-68399.

5. Wasserbauer, J. F., "Dynamte Response of a Mach 2.5 Axtsymmetric Inlet with Engtne or cold Plpe and Utilizing 60 percent Supersonic Internat Area Contraction," NASA TN $D-5338$, 1.969.

6. Barry, $\ddot{i}$. W. "Frequency of Supersonle Inlet Unstarts Due to Atmospherle Turbulence," Haml1ron Standard, Windsor locks, Conn., IISrR-5838, Oct.-1973; also NASA CR-13Z482.

7. Willoh, ..R. G., "A Mathematical Analysis of Supersonic Inlet Dynamics, NASA TN D-4969, 1968 .

8. Colc, G. I. and Willoh, R. G., "Analysis. of thi Dynamir Response of a Supersontc Inlet to Fluw-Field Perturbations Upstrean. of the Norinal Shock," NASA TN D-7839, 1975.

9. Cole, G. L., Dustin, M. O., and Nelner, G.. H., "A Throat Bypass Stability Syster Tested in a YF-12 Inlet," Journal of Alrcraft, Vol. 14, Jan. 1977, pp. 15-22.

10. Cubbison, R. W., Meieason, E. T., and Johnson, D. F," "Effect of Porous Bleed in. a HighPerformance Axisymmetric, Mixed-Compression Inlet at Mach 2.50," NASA TM X-1692, 1968.

11. Albers, J. A. and Olinger, 5. V., "YF-12 Propulsion Research Program and Results," Proceeding. of the SCAR Conference, NASA GP-001, Pt...1, 19.76, pp. 417-456.

12. Choby, D. A., "Tolerance of Mach 2.50 Axišnmmetric Mixed-Compression Inlets to Upstream Flow Vartations," NASA TM $\mathrm{X}-2433,1.972$. 


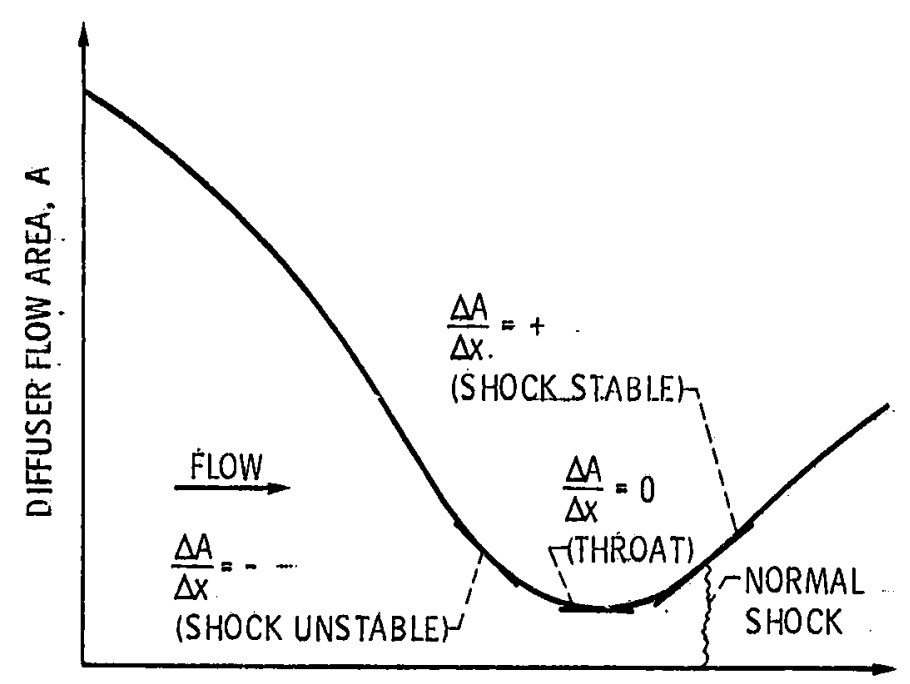

DISTANCE FROM COWL LIP, $x$

Figure 1. - Typical mixed-compression inlet diffuser flowarea variation.

in

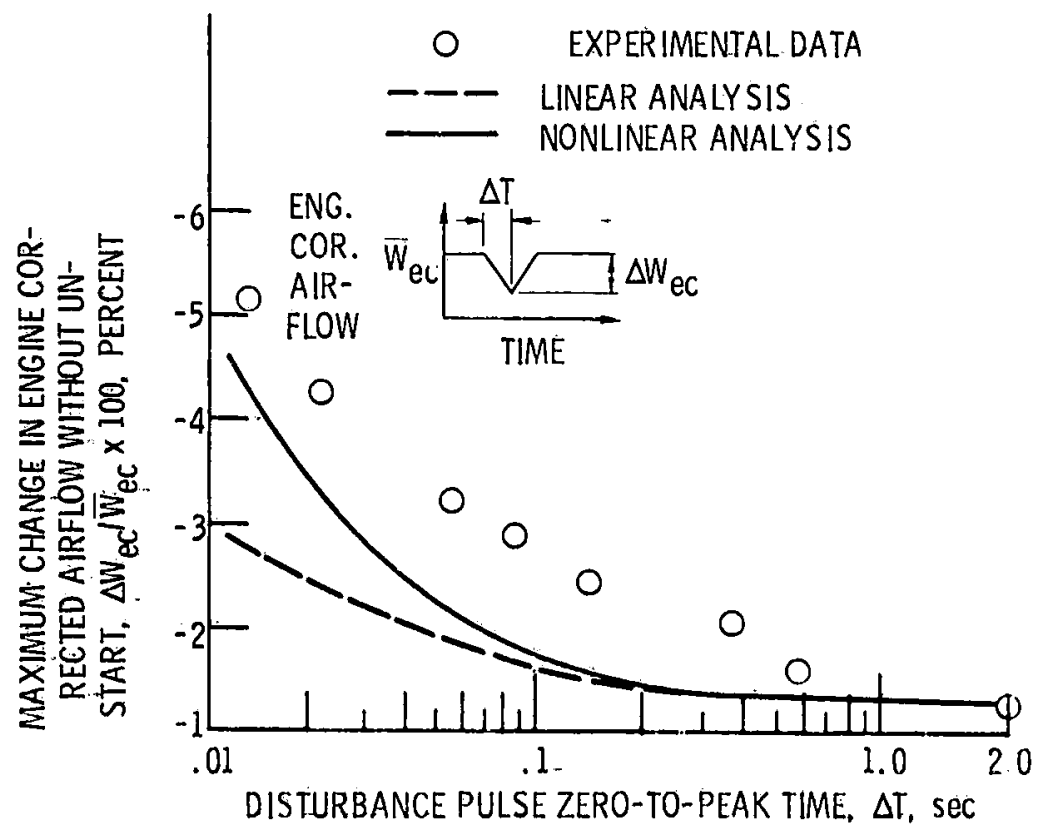

Figure 2. - Comparison of experimental and analysis r.esults of YF-12 in let response to engine corrected airflow disturbance. 


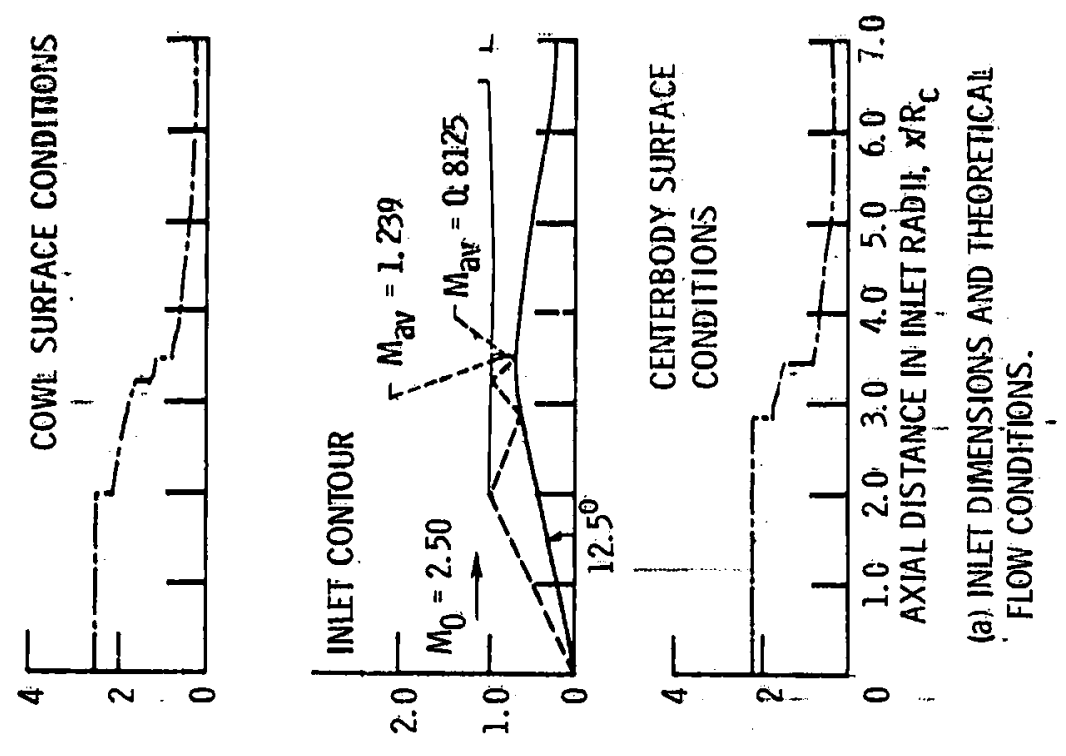

Jy/A. $\quad x_{W}$

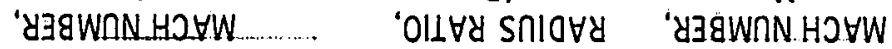

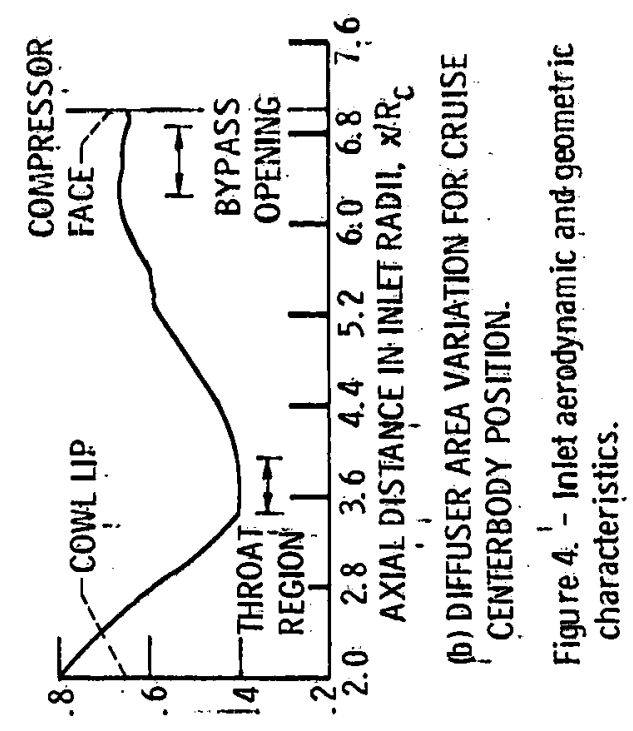

$\partial_{\forall} x_{\forall}$

'이바 $\forall \exists y \forall$ MOTI
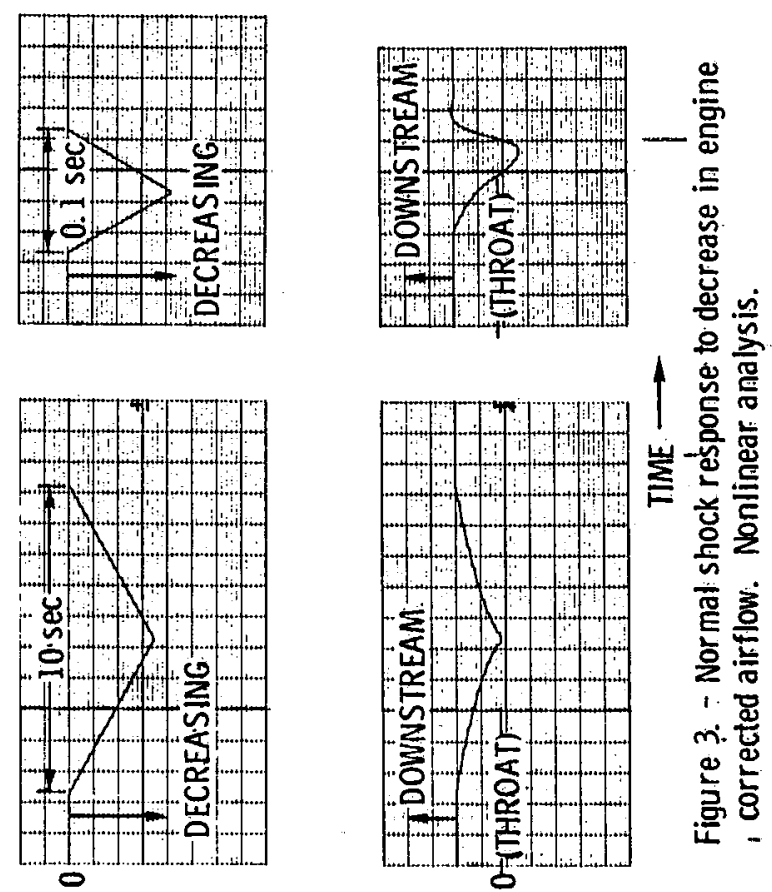

MOTy

$03103 \mathrm{Y} У 03$

$1 \forall 0$ YH 1
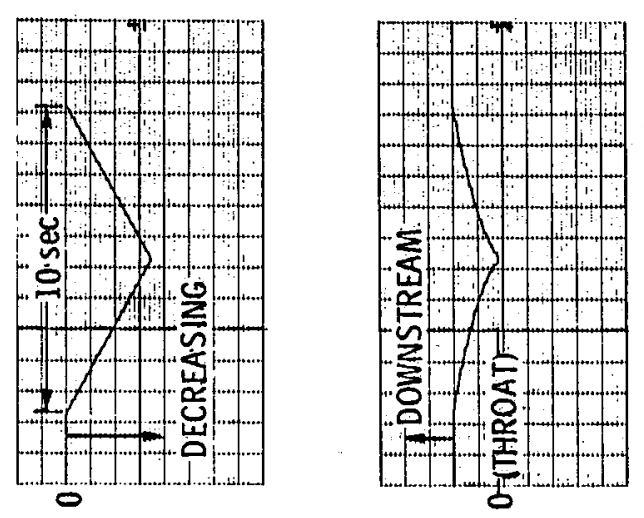

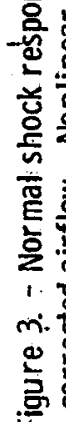

3NIONJ NI. ZONVHO

WOYJ $\exists J N \forall I S I O$

XJOHS T $\forall W Y O N$ 


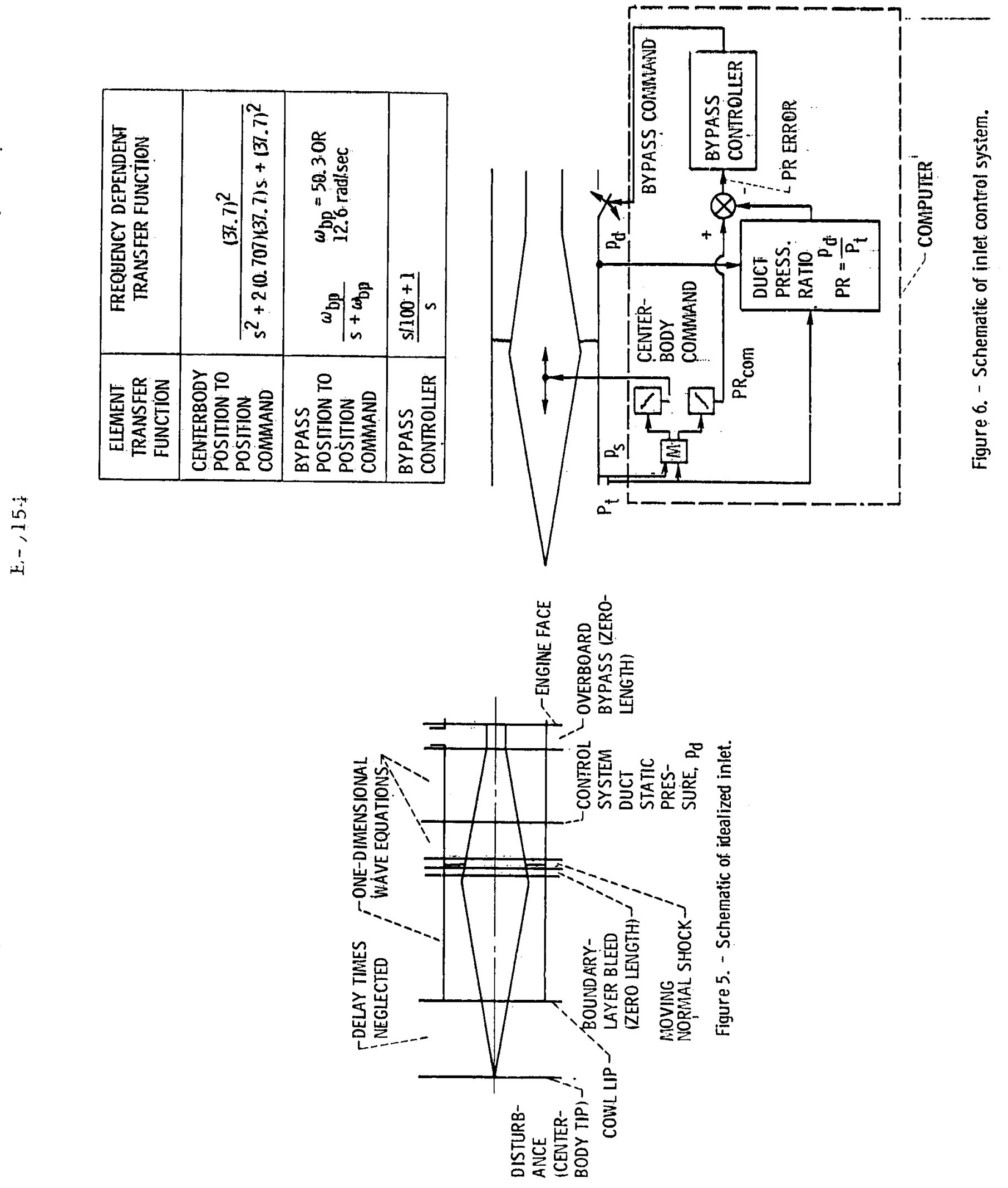



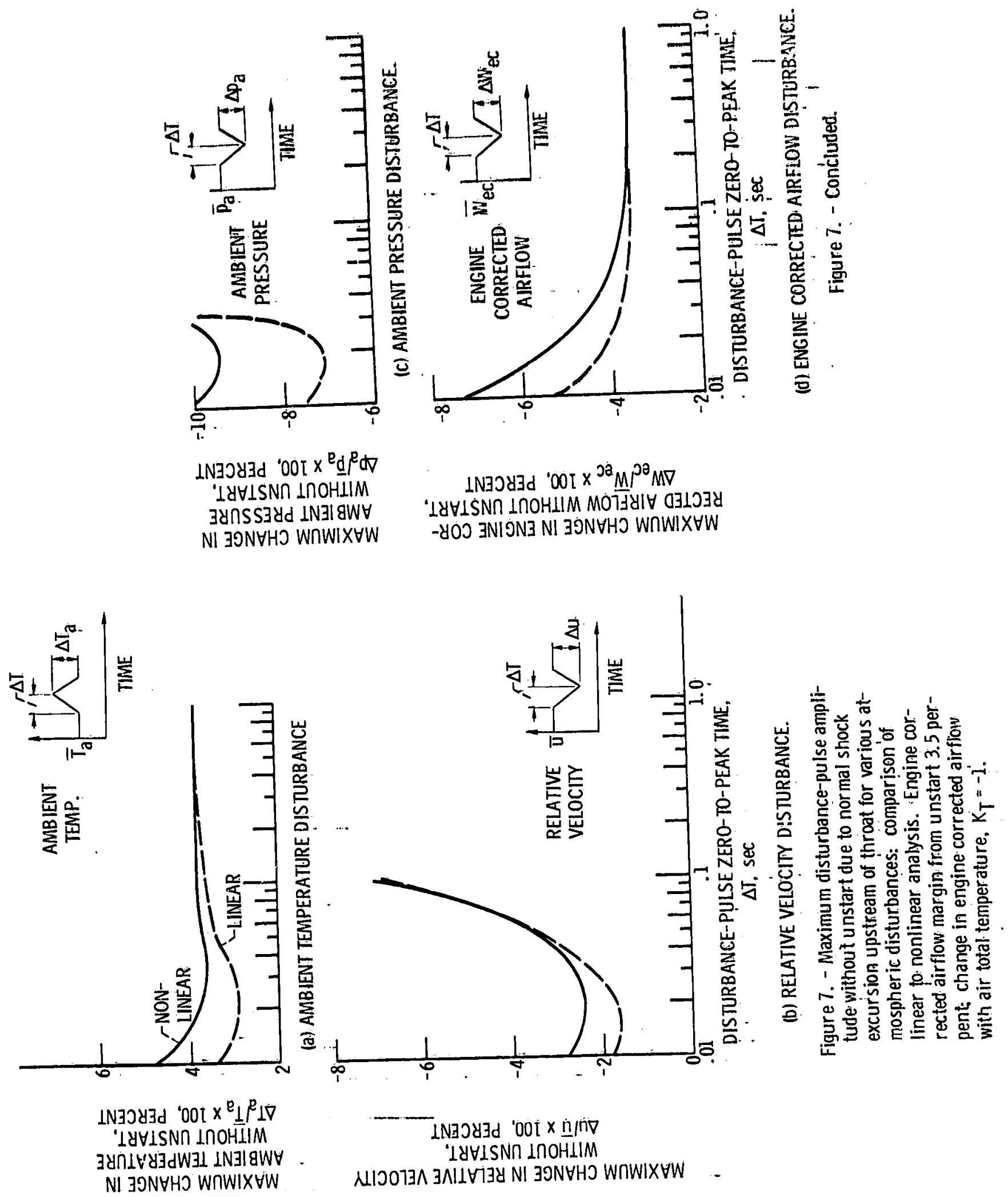

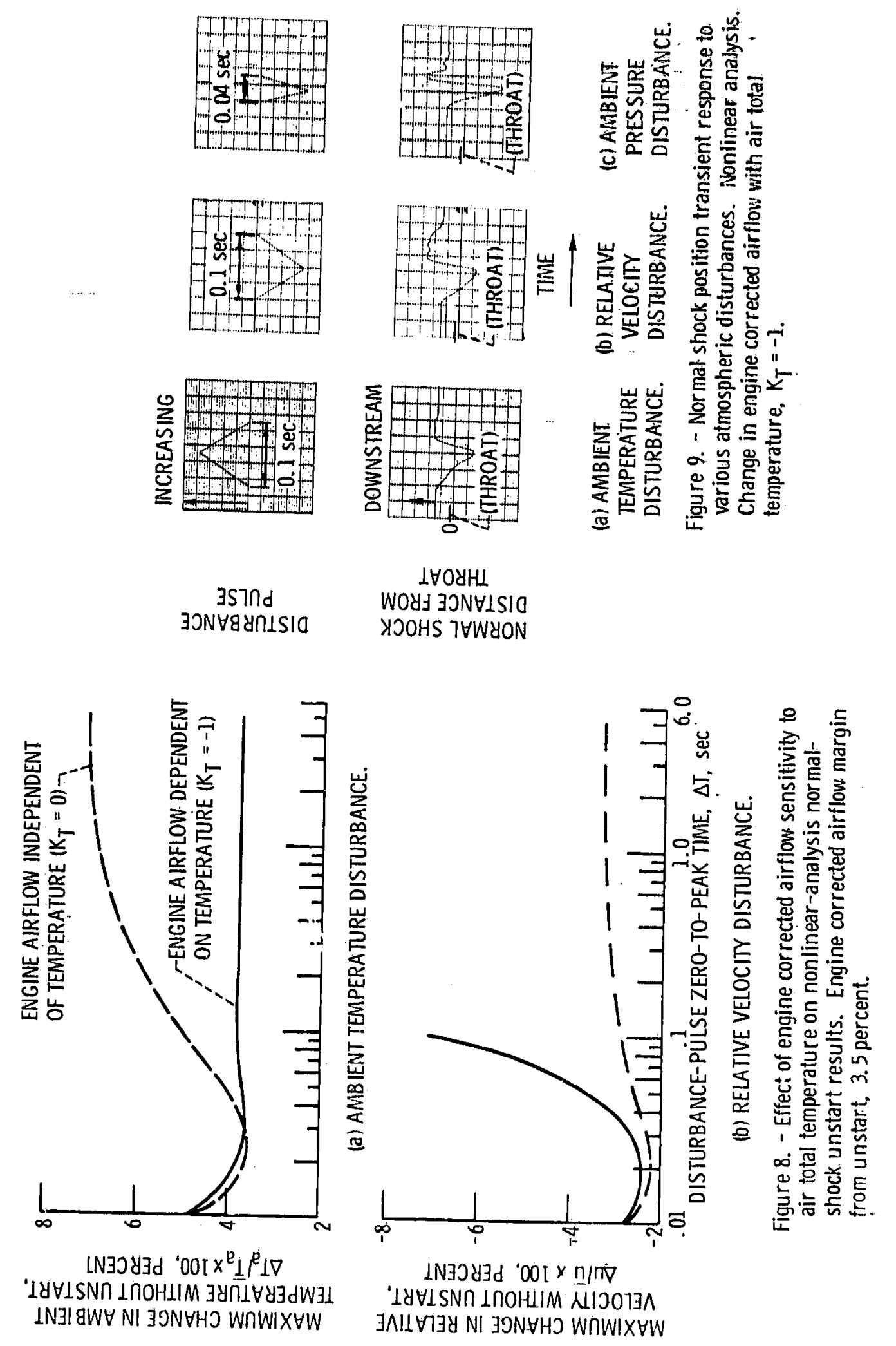


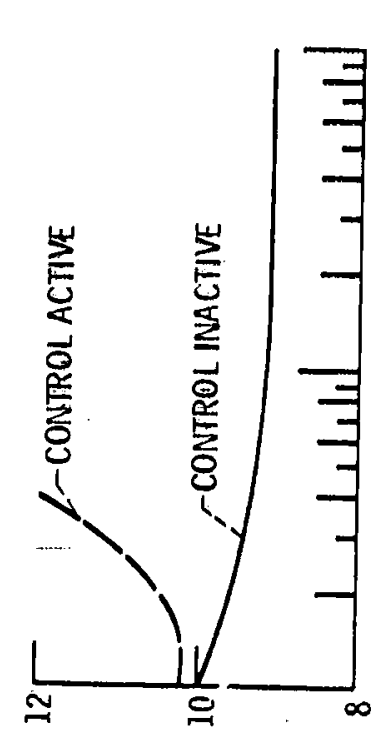

IN]JY 'IUVISN I OHIIM $\exists Y \cap \perp \forall Y \exists d W 3 \perp \perp N 318 W V$ NI $\exists$ IONHHJ WกWIX
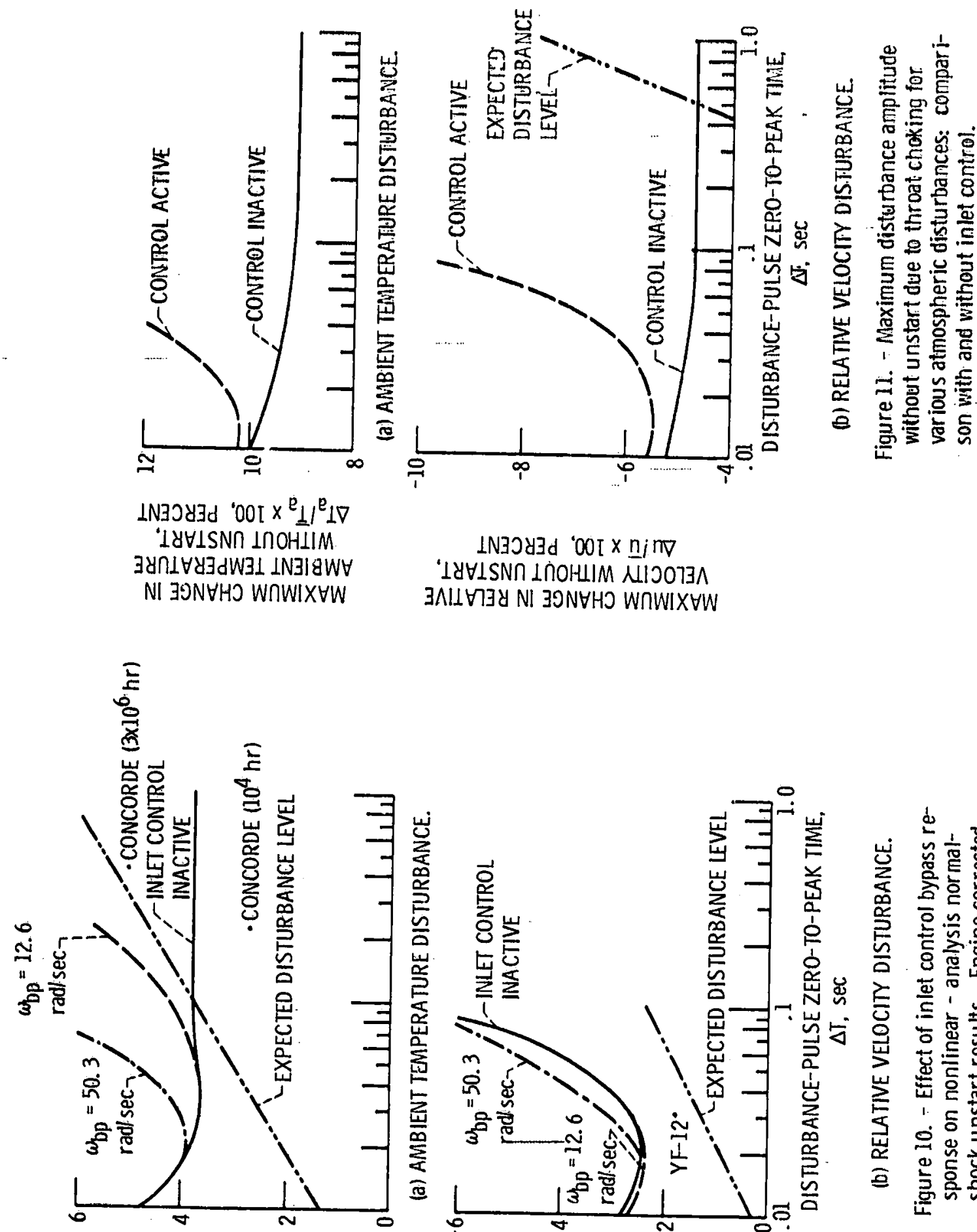

LNGJYYA '00[ $x \underline{n} i n \nabla$

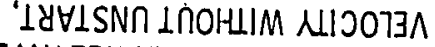

उAIL
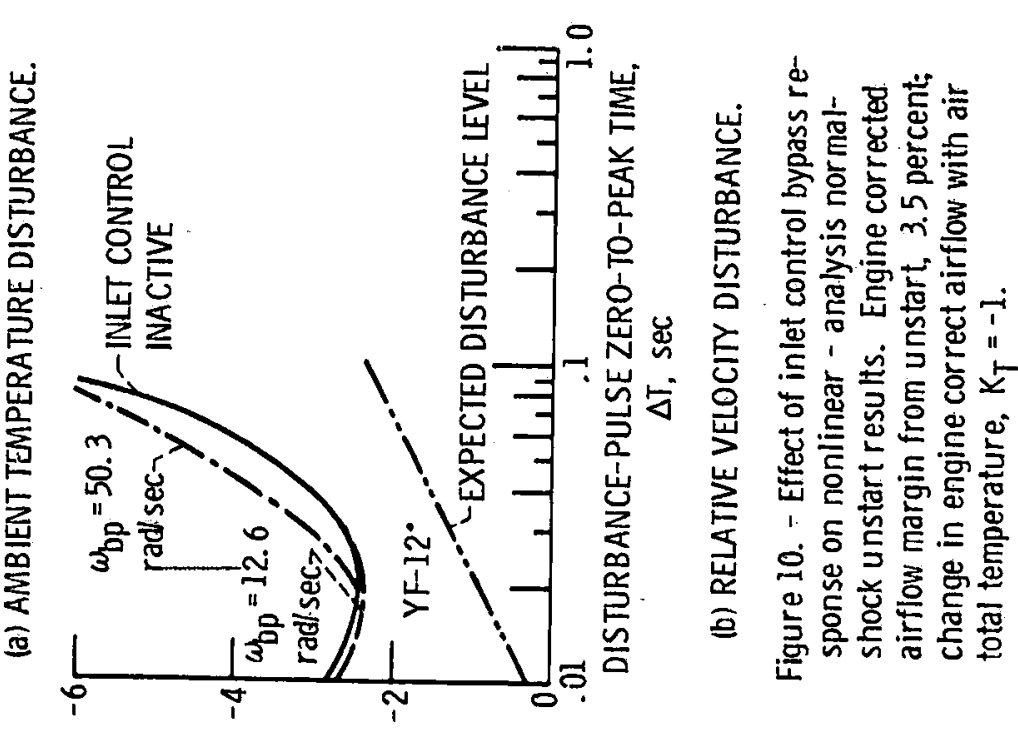

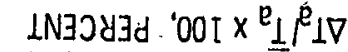

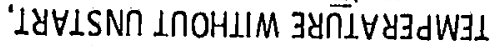

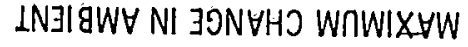

INבJYy '00t $x \underline{n} / \pi$

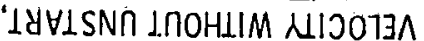
IAIL 